\title{
PELAYANAN KELUARGA BERENCANA PASCA PERSALINAN DALAM UPAYA MENDUKUNG PERCEPATAN PENURUNAN ANGKA KEMATIAN IBU
}

Friska Megawati Sitorus, Julia Mahdalena Siahaan

Kebidanan, Akademik Kebidanan Sari Mutiara, friska 77.sitorus@yahoo.co.id

\section{INFO ARTIKEL}

RiwayatArtikel:

Diterima: 22-07-2018

Disetujui: 05-08-2018

\section{Kata Kunci:}

Keluarga Berencana Pasca Persalinan

\section{ABSTRAK}

Abstrak : Masih rendahnya angka CPR ini berkaitan dengan masih tingginya unmet need. Tingginya unmet need pelayanan KB yakni 8,5\% dari jumlah pasangan usai subur (PUS), baik untuk membatasi kelahiran (4,6\%) mampu menjarangkan kelahiran (3,9\%) berpotensi besar untuk terjadinya kehamilan yang tidak diinginkan (KTD), oleh sebab itu dalam upaya meningkatkan kesehatan ibu, sasaran utama program KB adalah kelompok unmet need dan ibu pasca persalinan merupakan sasaran yang paling penting. KTD pada ibu pasca bersalin akan dihadapkan pada dua hal yang sama-sama beresiko. Keadaan ini akan menjadi kehamilan yang beresiko terhadap terjadinya komplikasi dalam kehamilan, persalinan dan nifas berikutnya dapat berkontribusi terhadap kematian ibu dan kematian bayi. Kedua, jika kehamilan diakhiri (aborsi, terutama jika dilakukan dengan tidak aman) maka berpeluang untuk terjadinya komplikasi aborsi yang juga dapat berkontribusi terhadap kematian ibu, oleh sebab itu KB pasca bersalin merupakan suatu upaya strategis dalam penurunan AKI dan juga AKB dan sekaligus penurunan TFR. Jenis penelitian yang adalah quasi eksperimen atau eksperimen semu dengan rancangan penelitian one grup pre test post ter. Rancangan ini bertujuan untuk melihat besarnya pengaruh perlakuan yang diberikan pada kelompok eksperimen pada saat pre test dan post test. Jumlah sampel yang digunakan 80 orang dengan menggunakan kuesioner sebagai instrumen penelitian. Hail penelitian menunjukan bahwa ada pengaruh dilakukannya koseling tentang KB pada ibu hamil terhadap pengetahuan dan minat ibu dalam mengunakan kontrasepsi setelah persalinan untuk menjarangkan kehamilan.

Abstract: The low Contraceptive Prevalence Rate (CPR) in the present day is often associated with the the high rate of unmet need. This high unmet need for family planning reaches $8.5 \%$ for couples of reproductive age, either to limiting (4.6\%) or to spacing birth (3.9\%). This condition brings great risk for unintended pregnancy to occur. Thus, in order to improve mother's health, the primary target of family planning is the unmet need group and postpartum mothers. The unintended pregnancy among postpartum mothers may cause two risks. The first is complication during pregnancy, childbirth, and postpartum which eventually may lead to death, either to the mother or the baby. The second is, if the pregnancy is terminated, particularly if the medical abortion is not safe, it may greatly result in abortion complications, which may also result in death. Therefore, using contraceptives after childbirth is highly recommended to reduce maternal and infant mortality rates, which, simultaneously, will reduce Total Fertility Rate (TFR). This was a quasi experimental study using one group pretest post-test design. This was to observe the effect of intervention which was given to the experimental group. A total of 80 respondents were selected as samples. The data was collected through administering questionnaire. It was obtained that there was an effect of counseling about family planning on pregnant mothers' knowledge and interest in using contraceptives after childbirth to space birth 


\section{A. LATAR BELAKANG}

Tujuan Millenium Development Goal (MDGs) 2015 adalah untuk meningkatkan kesehatan ibu dimana indikator utamanya penurunan angka kematian ibu menjadi 102 per 100.000 kelahiran hidup dan indikator proksinya adalah peningkatan persalinan yang ditolong oleh tenaga kesehatan menjadi 9\% pada tahun 2015. Selain pertolongan persalinan oleh tenaga kesehatan, penurunan kematian ibu dipengaruhi juga oleh keberhasilan pencapaian universal akses kesehatan reproduksi lainnya yang kemudian tertuang dalam MDG $5 \mathrm{~b}$ dengan indikator: CPR (contraceptive prevalence rate), ASFR (age specific fertility rate) 15-19 tahun, ANC (ante natal care) dan unmet need pelayanan KB.

Sejalan dengan Making Pregnancy Safer untuk penurunan angka kematian ibu, makaintervensi mengacu pada 3 pesan kunci pokok yaitu: 1) setiap persalinan ditolong oleh tenaga kesehatan terlatih, 2) setiap komplikasi obstetri neonatal mendapat penanganan yang adekuat, 3) setiap wanita usia subur mendapat akses terhadap pencegahan kehamilan yang diinginkan serta penanganan aborsi yang tidak aman. Berdasarkan studi lancet di negara-negara dengan tingkat kelahiran yang tinggi, keluarga berencana bermanfaat baik untuk kesehatan ibu dan bayi, dimana diperkirakan dapat menurunkan 32\% kematian ibu dengan mencegah kehamilan yang tidak diinginkan dan dapat menurunkan $10 \%$ kematian anak, dengan mengurangi jarak persalinan kurang dari 2 tahun (Cleland, Bernstein, Ezeh, Faundes, Glasier and innis, 2006).

Keluarga berencana (KB) dengan indikator CPR (contraceptive prevalencerate $=$ angka kesertaan berKB) dan unmet need pelayanan KB (pasangan usia subur yang membutuhkan pelayanan KB namun tidak dapat melaksanakannya dengan berbagai alasan) belakangan masuk dalam MDGs yang tertuang dalam MDG 5b (mewujudkan akses kesehatan reproduksi bagi semua pada tahun 2015). Adapun target yang ditetapkan untuk kedua indikator ini adalah meningkatkan CPR metode modern menjadi $65 \%$ dan menurunkan unmet need pelayanan KB menjadi 5\% pada tahun 2015.

Dua indikator KB diatas dalam sepuluh tahun terakhir tidak mengalami banyak kemajuan. CPR cara modern yang sudah meningkat pesat selama kurang lebih 10 tahun dari 47\% (SDKI 1991) menjadi 56,5\% (SDKI 2002) berarti peningkatan sebesar 9,5\% hanya naik 1,4\% menjadi $57,9 \%$ dalam kurun waktu10 tahun terakhir ini (SDKI 2012). Demikianjuga persentase unmet need yang sudah menurun pesat selama kurang lebih 10 tahun terakhir ini dari 12,7\% (SDKI 1991) menjadi 8,6 (SDKI 2002) berarti penurunan sebesar $4,1 \%$, malah meningkat $0,5 \%$ menjadi $9,1 \%$ (SDKI
2007), dan baru turun lagi sebesar $0,6 \%$ menjadi $8,5 \%$ (SDKI 2012), praktis penurunannya dalam kurun waktu 10 tahun terakhir ini hanya $0,1 \%$. Masih jauhnya target kedua indikator program $\mathrm{KB}$ ini patut diduga berkontribusi terhadap landainya penurunan AKI dimana program $\mathrm{KB}$ merupakan salah satu upaya penurunan AKI dibagai terdepan.

Masih rendahnya angka CPR ini berkaitan dengan masih tinginya unmet need. Tingginya unmet need pelayanan KB yakni 8,5\% dari jumlah pasangan usia subur (PUS), baik untuk membatasi kelahiran $(4,6 \%)$ maupun menjarangkan kelahiran $(3,9 \%)$ berpotensi besar untuk terjadinya kehamilan yang tidak diinginkan (KTD), oleh sebab itu dalam upaya meningkatkan kesehatan ibu, sasaran utama program KB adalah kelompok unmet need dan ibu pasca persalinan merupakan sasaran yang sangat penting. KTD apda ibu pasca persalinan akan dihadapkan pada dua hal yang sama-sama beresiko. Pertama, jika kehamilan diteruskan maka kehamilan tersebut akan berjarak sangat dekat dengan kehamilan sebelumnya, yang merupakan salah satu komponen " 4 terlalu" (terlalu muda, terlalu tua, terlalu banyak dan terlalu dekat). Keadaan ini akan menjadi kehamilan yang beresiko terhadap terjadinya komplikasi dalam kehamilan, persalinan dan nifas berikutnya yang dapat berkontribusi terahdap kematian ibu dan kematian bayi. Kedua, jika kehamilan diakhiri (aborsi, terutama jika dilakukan dengan tidak aman) maka berpeluang untuk terjadinya komplikasi aborsi yang juga dapat berkontribusi terhadap kematian ibu, oleh sebab itu KB pasca persalinan merupakan suatu upaya strategis dalam penurunan AKI dan juga AKB dan sekaligus penurunan TFR.

KB pasca persalinan sebenarnya bukan hal yang baru, karena sejak 2007, melalui program perencanaan persalinan dan pencegahan komplikasi (P4K) didalamnya terdapat amanat persalinan yang memuat tentang perencanaan penggunaan $\mathrm{KB}$ setelah bersalin. Penerapan KB pasca persalinan ini sangat penting karena kembalinya kesuburan pada seorang ibu setelah melahirkan tidak dapat diprediksi dan dapat terjadi sebelum datangnya siklus haid, bahkan pada wanita menyusui. Ovulasi pertama pada wanita tidak menyusui terjadi pada 34 hari pasca persalinan, bahkan dapat terjadi lebih awal. Hal ini menyebabkan pada masa menyusui, sering kali wanita mengalami kehamilan yang tidak diinginkan pada interval yang dekat dengan kehamilan sebelumnya. Kontrasepsi seharusnya sudah digunakan sebelum aktifitas seksual dimulai, oleh karena itu sangat strategis untuk memulai kontrasepsi seawal mungkin setelah persalinan.

Seorang ibu yang baru melahirkan bayi biasanya mudah untuk diajak menggunakan kontrasepsi, sehingga waktu setelah melahirkan adalah waktu yang 
paling tepat untuk mengajak seorang ibu menggunakan kontrasepsi. Tujuan pelayanan KB pasca persalinan adalah untuk mengatur jarak kehamilan/kelahiran dan menghindari kehamilan yang tidak diinginkan sehingga setiap keluarga dapat merencanakan kehamilan dengan aman dan sehat. Pelayanan KB pasca persalinan dimulai dengan pemberian informasi dan konseling yang sudah dimulai sejak masa kehamilan. Tenaga kesehatan sebagai pemberi pelayanan memegang peranan penting dalam memberikan informasi dan konseling KB pasca persalinan. Kurangnya akseptor keluarga berencana pasca persalinan dipengaruhi oleh pengetahuan ibu tentang KB. Pengetahuan dan pemahaman yang baik tentang KB pasca persalinan dapat mencegah peledakan penduduk dan mewujudkan keluarga yang sejahtera.

Walaupun semua metode kontrasepsi dapat digunakan sebagai metode KB pasca persalinan, namun mengingat drop out (DO) yang cukup tinggi dalam penggunaan non MKJP, maka dalam memberikan pelayanan konseling klien diarahkan untuk memilih metode kontrasepsi jangka panjang seperti implant dan IUD. Upaya intensif pengembangan KB pasca persalinan di Indonesia dilakukan pada tahun 2011 dimulai dengan penyusunan pedoman pelayanan $\mathrm{KB}$ apsca persalinan, penyusunan kurikulum pelatihan $\mathrm{KB}$ pasca persalinan, disamping hal tersebut diatas $\mathrm{KB}$ pasca persalinan diintegrasikan pula dalam $\mathrm{P} 4 \mathrm{~K}$, kelas ibu hamil dan pelayanan antenatal terpadu. Dalam pelayanan antenatal terpadu, tenaga kesehatan berkewajiban memberikan konseling KB pasca persalinan pada ibu hamil agar setelah bersalin dapat segera mendapatkan pelayanan KB.

Dalam kelas ibu hamil, salah satu materi yang dibahas adalah tentang KB pasca persalinan dan dalam 4 kali pertemuan, minimal satu kali pertemuan itu ibu hamil didampingi oleh suami atau keluarganya. Hal ini dimaksudkan agar kesehatan ibu selama hamil, bersalin dan nifas termasuk kesehatan bayi yang baru dilahirkan dan kebutuhan akan KB pasca persalinan menjadi perhatian dan tanggung jawab seluruh keluarga

Berdasarkan studi pendahuluan di Puskesmas Darussalam Medan, pada tahun 2015 didapatkan hasil terdapat PUS (pasangan usia subur) sebanyak 5.654 orang dan untuk cakupan KB pasca persalinan $66,6 \%$. Selain itu peneliti Juga melakukan pengambilan data studi pendahuluan bahwa dari $10 \mathrm{ibu}$ hamil, terdapat 4 ibu hamil (40\%) yang berminat menjadi akseptor KB pasca persalinan dan dari $10 \mathrm{ibu}$ hamil tersebut, terdapat 5 ibu hamil (50\%) yang mengetahui tentang KB pasca persalinan. Berdasarkan studi pendahuluan tersebut penulis berkeinginan untuk melakukan penelitian yang berjudul "Pelayanan Keluarga Berencana Dalam Pasca Persalinan Dalam Upaya Mendukung Percepatan Angka Kematian Ibu di Puskesmas Darussalam Medan."

\section{B. METODE PENELITIAN}

Penelitian ini menggunakan pendekatan kualitatif. Metode yang digunakan dalam penelitian ini adalah quasi eksperimen atau eksperimen semu. Rancangan penelitian ini menggunakan desain one group pre testpost test. Rancangan ini bertujuan untuk melihat besarnya pengaruh perlakukan yang diberikan pada kelompok eksperimen pada saat pre test dan post test. Populasi dalam penelitian ini adalah seluruh ibu hamil yang melakukan pemeriksaan kehamilan di Puskesmas Darussalam Medan. Variabel dalam penelitian ini adalah karakteristik responden, pengetahuan, minat ibu menggunakan kontrasepsi setelah persalinan serta kuesioner konseling tentang keluarga berencana. Data tersebut dianalisa menggunakan uji chi square.

\section{HASIL DAN PEMBAHASAN}

Analisis Univariat

\section{Karateristik Responden}

Tabel 1

Distribusi frekuensi berdasarkan karakteristik responden $(n=80)$

\begin{tabular}{llll}
\hline Variabel & & f & $\%$ \\
\hline Usia & $<$ 20 Tahun & 2 & 2,5 \\
& 20-35 Tahun & 64 & 92,5 \\
& $>$ 35 Tahun & 4 & 5 \\
Pendidikan & SMP & & \\
& SMA & 1 & 1.3 \\
& PERGURUAN & 18 & 22.5 \\
& TINGGI & 61 & 76.2 \\
& & &
\end{tabular}

\begin{tabular}{llcc} 
Pekerjaan & PNS & 26 & 32.5 \\
& Karyawan Swasta & 15 & 18.7 \\
& Wiraswasta & 5 & 6.3 \\
& Ibu Rumah Tangga & 34 & 42.5 \\
& & & \\
\hline Paritas & Primigravida & 15 & 18.8 \\
& Scundigravida & 35 & 43.8 \\
& Multigravida & 26 & 32.4 \\
& $\begin{array}{l}\text { Grandemultigravid } \\
\text { a }\end{array}$ & 4 & 5.0 \\
& & & \\
\hline
\end{tabular}

\begin{tabular}{llll} 
Minat & Ya & 67 & 83,7 \\
& & 5 \\
& Tidak & 13 & 16,2 \\
& & 5 \\
\hline
\end{tabular}


Tabel 2

Distribusi frekuensi berdasarkan pengetahuan responden $(n=80)$

\begin{tabular}{lll}
\hline Pengetahuan & f & \% \\
\hline Baik & 31 & 38,8 \\
Cukup & 41 & 51,3 \\
Kurang & 8 & 10 \\
\hline
\end{tabular}

\section{Minat Menjadi Akseptor KB}

Tabel 3

Distribusi frekuensi berdasarkan minat responden $(\mathrm{n}=80)$

\begin{tabular}{lll}
\hline Pengetahuan & $\mathbf{f}$ & $\mathbf{\%}$ \\
\hline Ya & 67 & 83,7 \\
Tidak & 13 & 16,3 \\
Total & 80 & 100 \\
\hline
\end{tabular}

\section{Konseling Tentang Keluarga Berencana} Tabel 4

Distribusi frekuensi berdasarkan konseling KB ( $\mathrm{n}=80)$

\begin{tabular}{ccc}
\hline Konseling KB & $\mathbf{f}$ & $\mathbf{\%}$ \\
\hline Tidak dilakukan & 15 & 18.8 \\
Dilakukan & 65 & 81.3 \\
\hline
\end{tabular}

\section{Analisis Bivariat}

\section{Pengaruh Konseling KB Terhadap Pengetahuan Responden tentang KB \\ Tabel 5}

Tabulasi silang konseling KB dengan Pengetahuan responden

\begin{tabular}{|c|c|c|c|c|c|c|}
\hline & & \multicolumn{3}{|c|}{$\begin{array}{l}\text { Pengetahuan } \\
\text { Responden }\end{array}$} & \multirow[b]{2}{*}{ Total } & \multirow[b]{2}{*}{ pValue } \\
\hline & & $\begin{array}{l}\mathrm{Ba} \\
\mathrm{ik}\end{array}$ & $\begin{array}{l}\text { Cuk } \\
\text { up }\end{array}$ & $\begin{array}{l}\mathrm{Ku} \\
\mathrm{ran} \\
\sigma\end{array}$ & & \\
\hline $\begin{array}{l}\text { Kon } \\
\text { seli }\end{array}$ & $\begin{array}{l}\text { Tidak } \\
\text { dilakukan }\end{array}$ & 1 & 9 & 5 & 15 & \multirow[t]{3}{*}{,000 } \\
\hline $\begin{array}{l}\text { ng } \\
\text { KB }\end{array}$ & Dilakukan & 30 & 32 & 3 & 65 & \\
\hline Total & & 31 & 41 & 8 & 80 & \\
\hline
\end{tabular}

\section{Pembahasan}

\section{Analisis Univariat}

Hasil penelitian menunjukkan bahwa umur responden mayoritas 20-35 tahun yaitu 92,5\%, pendidikan mayoritas perguruan tinggi yaitu $76,2 \%$, pekerjaan mayoritas adalah sebagai ibu rumah tangga yaitu 42,5\%, paritas mayoritas scundigravida yaitu $43,8 \%$ dan minat menggunakan kontrasepsi mayoritas responden mengatakan Ya (berminat) yaitu 83,75\%. Hasil penelitian ini menunjukkana bahwa responden di Puskesmas Darussalam Medan berada pada reproduksi sehat yaitu keadaan yang baik untuk hamil dan melahirkan serta menggunakan kontrasepsi, dan hasil penelitian juga menunjukkan bahwa responden mayoritas mengerti tentang kontrasepsi dan bersedia/berminat untuk menggunakan kontrasepsi setelah persalinan yang berguna untuk menjarangkan kehamilannya sehingga ibu dapat merawat bayinya dan juga menjaga kesehatan tubuhnya.

Hasil penelitian menunjukkan bahwa umur yang baik (tidak beresiko) dalam hamil, melahirkan dan ber-KB adalah 20-35 tahun, hal ini dikarenkan umur tersebut adalah saat yang baik untuk merencanakan kehamilan dan melahirkan sehingga diperlukan nantinya kontrasepsi dalam menjarangkan kehamilan berikutnya sesuai dengan program pemerintah yaitu 5 tahun. Kontrasepsi yang diperlukan adalah dengan jangka waktu yang panjang sehingga baik untuk ibu dalam merencanakan kehamilan berikutnya dan merawat dirinya serta mampu untuk mengasuh dan memberikan yang terbaik untuk anaknya sedangkan umur kurang dari 20 tahun adalah waktu yang kurang tepat dalam merencanakan kehamilan dan melahirkan karena dianggap organ reproduksi belum matang dan belum siap untuk melakukan konsepsi.

Hal ini sesuai dengan pendapat Ahmadi (2001) mengatakan bahwa Semakin bertambah usia akan semakin berkembang pula daya tangkap dan pola pikirnya, sehingga pengetahuan yang diperolehnya semakin membaik, akan tetapi pada umur-umur tertentu atau menjelang usia lanjut kemampuan penerimaan atau mengingat suatu pengetahuan akan berkurang sehingga mempengaruhi dalam melakukan sesuatu hal seperti pemilihan/pemakaian suatu metode kontrasepsi.

Hasil penelitian berdasarkan pengetahuan menunjukkan bahwa responden mayoritas cukup yaitu 41 orang $(51,3 \%)$, pengetahuan baik yaitu 31 orang $(38,8 \%)$ dan pengetahuan kurang yaitu 8 orang $(10 \%)$. Pengetahuan responden cukup dan baik berkaitan dengan pendidikan. Responden pada umumnya berpendidikan Perguruan tinggi sehingga pengetahuannnya sudah baik menerima informasi yang diberikan oleh orang lain (dalam hal ini petugas kesehatan). Menurut Notoadmodjo (2010) Pengetahuan merupakan hasil dari pada "tahu" dan ini terjadi setelah orang melakukan penginderaan terhadap suatu objek tertentu melalui panca indra manusia yakni indra penglihatan, penginderaan, penciuman, rasa dan raba yang diperoleh melalui mata dan telinga. Sebagian besar pengetahuan diperoleh melalui pendidikan, pengalaman sendiri maupun pengalaman orang lain, media massa maupun lingkungan. Pengetahuan terjadi setelah orang melakukan pengindraan terhadap suatu objek tertentu. Sebagian besar penginderaan manusia diperoleh melalui mata dan telinga. Pengetahuan 
kognitif merupakan domain yang sangat penting dalam membentuk tindakan seseorang (overt behavior) (Notoatmodjo, 2010)

Pengetahuan tentang kontrasepsi setelah persalinan mempengarui pola pikir ibu dalam memilih kontrasepsi apakah sesuai dengan kondisi dan kebutuhannya setelah mendapatkan informasi dari petugas kesehatan tentang jenis kontrasepsi untuk menjarangkan kehamilannya. Menurut Saifuddin (2005), bahwa pengetahuan ibu dipengaruhi oleh tingkat pendidikan. Saifuddin mengatakan bahwa semakin tinggi pendidikan seseorang maka semakin tinggi tingkat pemahamannya tentang sesuatu dalam hal ini tentang pemakaian IUD. Seseorang yang mempunyai tingkat pengetahuan yang luas khususnya tentang kesehatan maka seseorang itu akan cenderung dan senantiasa meningkatkan kesehatan diri, keluarga serta lingkungannya. Responden yang memiliki pengetahuan lebih luas maka akan lebih tahu untuk memilih metode kontrasepsi yang cocok untuk dipakainya dalam memakai kontrasepsi untuk menjarangkan kehamilan dalam waktu dan lama sehingga dapat meningkatkan kesejahteraan keluarganya.

Pelayanan KB pasca persalinan merupakan strategi yang penting dari kesehatan masyarakat dengan keuntungan yang signifikan terhadap ibu dan bayinya. Idealnya pemilihan kontrasepsi pasca persalinan, telah diperkenalkan pada saat kehamilan agar tidak terlambat untuk mendapatkannya karena pada umumnya wanita mulai menggunakan kontrasepsi pada minggu keenam pasca persalinan. Pelayanan KB pasca persalinan merupakan salah satu program strategi untuk menurunkan kehamilan yang tidak diinginkan.

Seorang wanita yang baru melahirkan bayi biasanya lebih mudah untuk diajak menggunakan kontrasepsi, sehinga waktu setelah melahirkan adalah waktu yang paling tepat untuk mengajak seorang ibu menggunakan kontrasepsi. Tujuan pelayanan KB pasca persalinan adalah untuk mengatur jarak kehamilan/kelahiran dan menghindari kehamilan yang tidak diinginkan, sehingga setiap keluarga dapat merencanakan kehamilan yang aman dan sehat. Pelayanan KB pasca persalinan dimulai dengan pemberian informasi dan konseling yang sudah dimulai sejak masa kehamilan. Tenaga kesehatan sebagai pemberi pelayanan memegang peranan penting dalam memberikan informasi dan konseling $\mathrm{KB}$ pasca persalinan kepada calon peserta KB

Dalam kelas ibu hamil, salah satu materi yang dibahas adalah tentang KB pasca persalinan dan dalam empat kali pertemuan, minimal satu kali pertemuan, ibu hamil didampingi oleh suami atau keluarganya. Hal ini dimaksudkan agar kesehatan ibu selama hamil, bersalin, nifas, termasuk kesehatan bayi yang baru dilahirkannya dan kebutuhan akan KB pasca persalinan menjadi perhatian dan tanggung jawab seluruh keluarga. Dalam P4K, ibu hamil dan keluarga diberi penjelasan tentang kesehatan maternal termasuk KB pasca persalinan dan diminta untuk menandatangani amanat persalinan yang salah satunya adalah kesepakatan tentang metode KB yang akan dipakainya kelak setelah persalinan. Namun dalai kenyataannya, pelayanan KB pasca persalinan ini belum terlaksana dengan baik, terbukti dengan cakupan pelayanan yang masih sangat rendah. Beberapa hal yang mengakibatkan ibu hamil tidak langsung menggunakan kontrasepsi yaitu, ingin menyusui secara ekskusif, memberikan ASI Eksklusif adalah sangat baik untuk bayi selain sebagai nutrisi utama untuk bayi, memperpanjang masa menyusui juga sebagai metode kontrasepsi yang dapat digunakan ibu.

\section{Analisis Bivariat}

Hasil penelitian menunjukkan bahwa mayoritas responden telah dilakukan konseling tentang jenis-jenis kontrasepsi untuk menjarangkan kehamilan yaitu 65 orang (81.3\%) dan minoritas tidak mendapatkan konseling yaitu 15 orang $(18,7 \%)$. Konseling adalah proses pertukaran informasi dan interaksi positif antara klien-petugas untuk membantu klien mengenali kebutuhannya memilih solusi terbaik dan membuat keputusan yang paling sesuai dengan kondisi yang sedang dihadapi. Proses konseling yang baik mempunyai empat unsur kegiatan (1) pembinaan hubungan yang baik, (2) penggalian dan pemberian informasi, (3) pengambilan keputusan, pemecahan masalah dan perencanaan, (4) menindaklanjuti pertemuan.

Dalam pelayanan KB pasca persalinan, sebelum mendapatkan pelayanan kontrasepsi, klien dan pasangannya harus mendapatkan informasi dari petugas kesehatan secara lengkap, jelas dan benar agar dapat menentukan pilihannya dengan tepat. Pelayanan KB pasca persalinan akan berjalan dengan baik bila didahului dengan konseling yang baik, dimana klien berada dalam kondisi yang sehat, sadar dan tidak dibawah tekanan ataupun tidak dalam keadaan kesakitan.

Konseling pelayanan KB pasca persalinan dapat menggunakan media lembar balik alat bantu, pengambilan keputusan (ABPK) ber-KB. Konseling KB pasca persalinan ini dapat dilaksanakan pada waktu pemeriksaan kehamilan saat mengisi amanat persalinan dalai P4K dan saat mengikuti kelas ibu hamil, selama proses perslainan, pasca persalinan dan sebelum/sesudah pelayanan kontrasepsi. Setelah dilakukan konseling dan sudah ditentukan metode kontrasepsi yang dipilih, klien memberikan persetujuannya berupa tanda tangan pada lembar persetujuan tindakan medis (informed consent) untuk 
metode KB AKDR, Implant serta kontrasepsi mantap (tubektomie dan vasektomi).

\section{SIMPULAN DAN SARAN}

Kesimpulan yang dibuat dalam penelitian tentang pelayanan KB pasca persalinan dalam upaya mendukung percepatan penurunan angka kematian ibu di Puskesmas Darussalam Medan, maka dapat dibuat suatu kesimpulan sebagai berikut: Hasil analisis univariat mayoritas berumur 20-35 tahun yaitu 92,5\%, berdasarkan pendidikan mayoritas perguruan tinggi yaitu $76,2 \%$, berdasarkan pekerjaan mayoritas sebagai ibu rumah tangga yaitu 42,5\%, berdasarkan paritas mayoritas scundigravida yaitu 43,8\%.Hasil analisis berdasarkan minat (keinginan) untuk menggunakan kontrasepsi setelah persalinan mayoritas responden mengatakan (Ya) berkeinginan untuk ber-KB yaitu 83,7\%.

Hasil analisis bivariat berdasarkan pengaruh terhadap pengetahuan konseling $\mathrm{KB}$ pada masa kehamilan didapatkan bahwa mayoritas pengetahuan responden terhadap KB cukup setelah dilakukannya konseling tentang KB. Setelah dianalisa secara statistik maka diperoleh nilai $\mathrm{P}$ 0,000 yang artinya ada pengaruh dilakukannya konseling tentang $\mathrm{KB}$ pasca persalinan dengan pengetahuan responden tentang $\mathrm{KB}$ pasca persalinan

\section{UCAPAN TERIMA KASIH}

Tim penulis mengucapkan terima kasih kepada Lembaga Penelitian dan Pengabdian Masyarakat (LPPM) Universitas Sari Mutiara Indonesia, dan Kepada Pimpinan Puskesmas Darussalam Medan.

\section{DAFTAR RUJUKAN}

[1] Atikah Proverawati, dkk, 2010, Panduan Memilih Kontrasepsi, Nuha Medika, Yogyakarta

[2] Ari Sulistyawati, 2011, Pelayanan Keluarga Berencana, Salemba Medika, Jakarta

[3] Ahmadi, Abu, 2007, Sosiologi Pendidikan, Rineka Cipta, Jakarta

[4] Djaali, 2007, Psikologi Pendidikan, Bumi Aksara, Jakarta

[5] Heri P (1998), Pengantar Perilaku Manusia, EGC, Jakarta
[6] Inti Mujiati, 2013, Situasi KB di Indonesia, Buletin, Data dan Informasi Kesehatan, Kementrian Kesehatan RI, Jakarta

[7] Indrayani, 2009, Buku Ajar Asuhan Kehamilan, Trans Info Media, Jakarta

[8] Mandriwati, 2002, Asuhan Kehamilan Antenatal, EGC, Jakarta

[9] Niken Meilani, dkk, 2010, Pelayanan Keluarga Berencana, Fitramaya, Yogyakarta

[10] Notoadmojo, 2010, Ilmu Perilaku Kesehatan, Rineka Cipta, Jakarta

[11] _ 2010, Promosi Kesehatan Teori dan Aplikasi Rineka Cipta, Jakarta

[12] Nursalam, 2008, Konsep dan Penerapan Metodologi Penelitian, Salemba Medika, Jakarta

[13] Sry Handayani, 2010, Pelayanan Keluarga Berencana, Pustaka Rihama Yogyakarta

[14] Sopiyudin Dahlan, 2011, Statistik Untuk Kedokteran Dan Kesehatan, Salemba Medika, Jakarta

[15] Uno, Hamzah, 2012, Teori Motivasi dan Pengukurannya Bumi Aksara, Jakarta

[16] Yeni Kusmiati, Sujiyati, 2009, Perawatan Ibu Hamil, Fitramaya, Yogyakarta

[17] tlab. Prosiding Seminar Nasional IKIP Mataram, Mataram, Indonesia, h. 12-14, Oktober 2017.

\section{PROFIL PENULIS UTAMA}

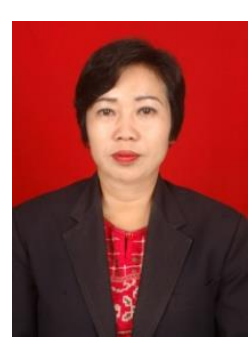

Friska Megawati Sitorus, lahir di Jakarta 27 Juli 1977. Riwayat pendidikan: lulus dari SPK Balimbingan (1996), Program Pendidikan Bidan Sari Mutiara (1998), Akademi Kebidanan Sari Mutiara Medan (2000), D-IV Bidan Pendidik UGM Yogyakarta (2002) dan Magister Kesehatan Masyarakat di Universitas Sari Mutiara Indonesia (2014). Dosen pengajar di Akademi kebidanan Sari Mutiara Medan (2003 - sekarang). Pernah mendapatkan hibah ristekdikti penelitian dosen pemula dan penulisan buku ajar tahun 2016, dan mendapatkan hibah penelitian dosen pemula tahun 2017 